\title{
APLICACIÓN DE TÉCNICAS DE BIOLOGÍA MOLECULAR A LA INVESTIGACIÓN OFTALMOLÓGICA
}

\author{
APPLYING MOLECULAR BIOLOGY TECHNIQUES TO \\ OPHTHALMOLOGIC RESEARCH
}

\author{
DE-DIEGO JG ${ }^{1}$, RODRÍGUEZ FD ${ }^{1}$
}

Actualmente, aparecen registradas más de 990 enfermedades hereditarias en las que el ojo se ve afectado de forma exclusiva o en el contexto de una enfermedad que aqueja a otros órganos (1). La aniridia, el glaucoma congénito primario, el retinoblastoma, la neuropatía de Leber, o el melanoma uveal constituyen algunos ejemplos. En algunos casos, la afectación se atribuye a una mutación en un gen específico; en otros, se relaciona con cambios en diferentes secuencias de DNA que aumentan la susceptibilidad a padecer una enfermedad. En ocasiones, la enfermedad hereditaria constituye en realidad un grupo de enfermedades que se transmiten con diferentes patrones hereditarios en las que se ven implicados decenas de loci (por ejemplo, la Retinitis pigmentosa).

Son numerosas las aplicaciones que la Biología Molecular ofrece a la investigación médica y, en particular, a la investigación oftalmológica básica, clínica y aplicada. Proporciona la posibilidad de estudiar enfermedades de origen genético para facilitar el hallazgo de patrones de variabilidad genética y de expresión proteica que permitan un mejor conocimiento de la enfermedad y sirvan de ayuda en el diagnóstico preciso, el pronóstico ajustado o el abordaje terapéutico eficaz. Por ejemplo, el análisis de la secuencias de DNA en regiones específicas del genoma y la determinación de variantes en la disposición de uno o varios nucleótidos (polimorfismos) constituye una herramienta muy útil para el diagnóstico de enfermedades oculares en poblaciones o en grupos familiares. Mediante la selección de organismos que sufren una mutación espontánea o tras la manipulación externa del DNA, como explicaremos a continuación, se han obtenido modelos animales que nos sirven para analizar los mecanismos moleculares subyacentes a una entidad nosológica (2). Por otra parte, esta táctica abre las puertas a la terapia génica somática que pretende restaurar la función ausente, debilitada o alterada de un gen o grupo de genes.

Indudablemente, la Biología Molecular, a lo largo de su desarrollo, ha suministrado y suministra a la Oftalmología herramientas metodológicas de gran utilidad.

El DNA, la molécula encargada de transmitir la información genética, desempeña, sin embargo, un papel básicamente pasivo. Son las proteínas resultantes de su expresión las encargadas de llevar a cabo las miles de reacciones que sustentan la vida. Por ello, resulta esencial avanzar en el conocimiento de la función proteica.

Los organismos mutantes han proporcionado algunas de las claves sobre la función de las proteínas. Tradicionalmente, se han obtenido mutaciones mediante tratamiento con agentes mutagénicos (determinadas substancias químicas, radiaciones...). Es posible, además, producir mutantes específicos insertando en un organismo vivo copias de genes alteradas o no funcionales para examinar los cambios que inducen en su comportamiento o en su desarrollo. Este tipo de experiencias se han realizado con diferentes organismos. Sin embargo, teniendo en cuenta que el ratón comparte aproximadamente un 99\% de sus genes con los humanos y la rapidez con la que esta especie se reproduce, constituye un

Departamento de Bioquímica y Biología Molecular. Grupo de Investigación Reconocido «Bases Moleculares del Desarrollo» (GIR-BMD).

Universidad de Salamanca. Salamanca. España.

1 Profesor Titular de Bioquímica y Biología Molecular

e-mail: dediego@usal.es / lario@usal.es 
modelo muy adecuado para realizar estudios funcionales. La publicación en 1982 en la portada de la revista Nature (3) de la fotografía de un ratón transgénico gigante supuso un verdadero hito para la Biología Molecular.

Un ratón transgénico es aquel que lleva insertado en su genoma un gen exógeno (transgén); es decir, un gen construido en el laboratorio mediante la tecnología del DNA recombinante y posteriormente introducido en el genoma del ratón. Se pueden obtener ratones transgénicos mediante dos métodos: transformando con el DNA de interés cultivos celulares de células madre embrionarias (células ES) o inyectando el gen deseado en el pronúcleo de un huevo de ratón fertilizado.

El primero de estos métodos se lo debemos a Mario R. Capecchi, Oliver Smithies y Martin J. Evans (4). Los tres compartieron el premio Nobel de Fisiología o Medicina en 2007. Se comienza aislando células madre embrionarias a partir de embriones tempranos de ratón. Estas células son pluripotentes; es decir, poseen la capacidad para producir cualquier tipo de célula del animal maduro, incluyendo los gametos, y pueden ser cultivadas en el laboratorio. Se construye entonces el gen cuya función nos interesa conocer uniéndolo a un DNA vector cuya misión es la de facilitar su inserción en el genoma del ratón. Se incluyen también secuencias promotoras y potenciadoras que permitirán la expresión del gen. Cuando las células ES de ratón cultivadas se pongan en contacto con la construcción de DNA exógeno, ésta se incorporará en su genoma. La incorporación puede ocurrir al azar, en cualquier lugar. Sin embargo, si se introducen en el vector algunas secuencias de los extremos del gen de interés, es posible insertarlo de forma dirigida, en el lugar que ese gen ocupa habitualmente en el cromosoma (recombinación homóloga). La inserción ocurre en un exón esencial del gen endógeno por lo que éste resultará inactivado. Las células ES transformadas de este modo se reintroducen en blastocistos (por microinyección o co-cultivo) para obtener embriones quiméricos (parte de las células corresponden al embrión hospedador y parte derivan de las células ES transformadas). Estos embriones se implantan en el útero de hembras pseudopreñadas (i.e. hembras en las que se han inducido los cambios hormonales necesarios para hacer su útero receptivo). En algunas de estas hembras (menos de la tercera parte) la implantación ocurrirá y se desarrollará un ratón. Se comprueba entonces, en una muestra de tejido, cuáles de estos ratones poseen efectivamente el gen exógeno (lo cual ocurre habitualmente en menos del 10\% de ellos). Estos ratones serán heterocigóticos, pero mediante cruzamientos se pueden obtener líneas de homocigotos que permitan evaluar el efecto del transgén de forma completa. En el segundo método, demostrado por varios investigadores a principios de los años 80 del siglo pasado, el gen de interés se prepara de la misma forma que en el caso anterior pero se inyecta con una microaguja en el pronúcleo masculino (de mayor tamaño que el femenino) de un huevo fertilizado. Ambos pronúcleos se fusionarán formando un cigoto diploide. Cuando el cigoto se divida originando un embrión de dos células será el momento de implantarlo en una hembra pseudopreñada. Las siguientes etapas son idénticas a las del primer método.

Cuando el gen exógeno es un gen no funcional (alelo nulo) ambas copias del gen resultan anuladas en la línea de ratones homocigóticos. Estos ratones, en los que se ha eliminado la actividad de un gen, se denominan knockout y su fenotipo (apariencia, comportamiento u otras características bioquímicas observables) resulta de particular interés para determinar cuál es la función fisiológica del gen anulado en el ratón y, por extrapolación, en el hombre. La contrapartida de los ratones knock-out son los knock-in. En ellos se reemplaza un gen propio del ratón por otro cuya función se desea conocer o bien se eliminan determinadas secuencias que bloquean la transcripción de un gen para conseguir que éste se exprese en determinados tejidos o en determinadas etapas del desarrollo.

Entre las limitaciones de esta técnica está, por ejemplo, el hecho de que algunos ratones no parecen afectados por la anulación de alguno de sus genes. El genoma del ratón parece ser lo bastante redundante para compensar la pérdida. Además, la mayoría de los genes son pleiotrópicos; es decir, provocan un conjunto de efectos fenotípicos no relacionados, se expresan en diferentes tejidos o en distintas etapas del desarrollo. Por otra parte, en un $15 \%$ de los casos no se consigue obtener un individuo adulto, lo cual restringe el estudio al período embrionario (o a parte de él) dificultando el conocimiento de la función del gen en el adulto y, por tanto, la extrapolación a la salud humana. A pesar de estas limitaciones, los ratones knockout resultan excelentes modelos para investigar enfermedades humanas relacionadas con la pérdida de función de 
un gen. Todos estos hallazgos repercutirán, sin duda, en la mejora de las estrategias para el diagnóstico, tratamiento y prevención de muchas enfermedades humanas.

\section{BIBLIOGRAFÍA}

1. OMIM (Online Mendelian Inheritance in Man). http://www.ncbi.nlm.nih.gov/omim consultado el 5 de febrero de 2009.
2. Hafezi F, Grimm C, Simmen BC, Remé CE. Molecular ophthalmology: an update on animal models for retinal degenerations and dystrophies. Br J Ophthalmol 2000; 84: 922-927.

3. Palmiter RD, Brinster RL, Hammer RE, Trumbauer ME, Rosenfeld MG, Birnberg NC, et al. Dramatic growth of mice that develop from eggs microinjected with metallothionein-growth hormone fusion genes. Nature 1982; 300: 611-615.

4. Thomas KR, Capecchi MR. Site-directed mutagenesis by gene targeting in mouse embryo-derived stem cells. Cell 1987; 51: 503-512. 